\title{
The Effects of Fairness on Online Customer Repurchase Intention
}

\author{
Yuping LI \\ School of Business Planning, \\ Chongqing Technology and Business University, \\ Chongqing China \\ ctbulyp@163.com
}

\begin{abstract}
This article discusses the effect of the fairness which can be constituted by distributive fairness, procedural fairness, interpersonal fairness and informational fairness on trust, satisfaction and customer repurchase intention in ecommerce from the perspective of fairness theory. It adapts questionnaire to collect data and testifies the hypothesis by structural equation model. The results show that online customer fairness has a significant positive effect on online customer trust; online customer trust has a significant positive effect on online customer satisfaction; online customer satisfaction has a significant positive effect on online customer repurchase intention. The research not only deepens the application of fairness theory in e-commerce, but also makes some suggestion to the development of e-commerce enterprises.
\end{abstract}

Keywords-fairness; trust; satisfaction; repurchase intention; e-commerce

\section{INTRODUCTION}

Online customer repurchase intention is the dominant issue in the field of service marketing and the profit produced by repurchase customers is as five times as many new customers, but Kim and Gupta (2009) ${ }^{[1]}$ considered that more than $50 \%$ repeat purchase customers rarely bought three times. The main marketing activities of the enterprise have switched from inducing customers to stimulating customer repurchase intention and maintaining long-term buyer-seller relationship. Although customer repurchase intention had been widely appreciated in previous studies, the research about influencing factors of customer repurchase intention in online environment is still limited.

Fairness is the foundation of all trades, and when consumers face the external and internal uncertainty, the fairness is more important. Because of the high degree of risk and instability in online shopping, customer equity is particularly important. The perceived equity can enhance customer confidence in e-commerce enterprises and provide a good foundation for the long-term relationship development between customer and electronic commerce. In consumer behavior research, the fair was always used to explain the consumer behavior. Chiu et al. (2007) ${ }^{[2]}$ and Chiu et al. (2009)

Project Supported by Scientific and Technological Research Program of Chongqing Municipal Education Commission (KJ1600612); Project Supported by Social and Scientific Research Program of Chongqing Municipal Education Commission (17SKG096); Project Supported by Socia Science Planning Program of Chongqing (2016BS033); Project Supported by School-based Program of Chongqing Business and Technology University (670101553)
[3] discussed the important influence of fairness, trust and satisfaction on online customer behavior, but most of these studies divided the fair into a single dimension or first-order potential construct, in fact the fair explained by distributive fairness, procedural fairness, interpersonal fairness and information fairness may also see as a second order variable to directly affect the trust. Therefore, the research purpose is to explore the continuity effect of fairness interpreted by distributive fairness, procedural fairness, interpersonal fairness and information fairness on the trust, satisfaction and repeat purchase intention.

\section{THEORY AND HYPOTHESES}

Fair is put forward at the earliest by Homans (1961), and mainly be understood as distributive fairness or perceive the fairness of the result. Homans (1961) argue that fair refers that there is proportionate to pay and reward in the relationship. Because the allocation fairness only focuses on the result and ignores the whole process of trading, Thibaut and Walker (1975) proposed the concept of fairness based on the study of fairness perceptions between different procedural and trial process and at last put forward the two concepts of procedural fairness, namely, process control and decision control. According to the characteristics of the distribution procedures and process, Leventhal (1980) put forward the six principles of procedural fairness, respectively, the consistency principle, bias suppression principle, principles of accuracy, the principle of change, the principle of representativeness, moral and ethical principle. Folger and Greenberg (1985) argue that procedure fairness refers to the process of produce fair results. These two dimensions (distributive fairness and procedural fairness) always occupy the dominant position in the field of psychology and marketing. Later Bies and Moag (1986) proposed a concept of interactive fair and they think that the interactive fairness refers to the influence of the executive way and attitude on employees' fairness perception in the process of execution. Chiu et al. (2009) ${ }^{[3]}$ argued that interactive fair represent whether online customer was treated with respect, warm and friendly by online retailer or service personnel. Greenberg (1993) argues that interactive fair consists of two aspects: interpersonal fairness and information fairness. Interpersonal fairness reflects the extent that people were treated politely, with dignity and respect, but information fairness is the fairness perceptions in the process of information acquisition and allocation. 
Although at present the research on fair has been very mature, but fair structure problem has no clear explanation and consistent conclusion. According to the researches of the scholars, there are four main structure dimensions. On the first is the single factor, it advocates the fair is a single structure, and think that the meaning of the linkage between distributive fairness and procedure fairness is too tight to distinguish this from the empirical study; The second is the two-factor theory, and the typical researchers is Thibaut and Walker (1975) study. In the article they think that distributive fairness and procedural fairness is two dimensions of fair; The third is the three factors theory which was put forward by Masterson (2000), and fair is made up of these three parts, respectively, distributive fairness, procedural fairness and interaction fairness. Fourth is the four factors theory put forward by Colquitt (2001) which think fair is divided into distributive fairness, procedural fairness, interpersonal fairness and information fairness. This research use four dimension structure of fairness to discuss the effect of fairness on the customer repurchase intention in online shopping.

According to the integration of technology acceptance model and fairness theory to understand customer loyalty to online environment, Chiu et al. (2009) pointed that the distributive fairness, procedural fairness and interaction fairness significantly influence online customer trust, and further affect customer satisfaction, in addition, perceived usefulness and customer satisfaction influence online customer loyalty; on the basis of the integration of expectation inconsistent theory and equity theory to discuss the continuity of knowledge sharing motivation in virtual community research, Chiu et al. (2011) indicated that the self-worth of expectation inconsistent, distributive fairness and interactive fairness can affect the satisfaction of virtual community members; based on the second order construct of psychological contract violation, Chiu et al. (2013) ${ }^{[5]}$ discussed the effect of psychological contract violation on trust and satisfaction, in turn, on repeat purchase intention, and distribution unfairness, procedural unfairness, interpersonal unfairness and information unfairness as the first-order concept influence the psychological contract violation.

Boulding et al. (1993) ${ }^{[6]}$ argues that there are two concepts of customer satisfaction: specific trading customer satisfaction and cumulative customer satisfaction. Specific trading customer satisfaction is the post-purchase evaluation of perception for a specific purchase and the cumulative customer satisfaction is an integrated evaluation of the brand according to a period of purchase and use experience. The former may provide specific diagnostic information about the recipients of the product or service and the latter is a company's overall customer service quality evaluation index. Oliver (1980) suggested that customer satisfaction is the state of feeling which formed by the comparison performance with expectation after the consumption of products and services. Satisfaction is a kind of emotional reaction and the reaction causes people to focus on specific goals and influence their behavior that is going on. Expect consistency theory thought that satisfied customers will have high expectations for future purchases and the likelihood of repeat purchase may be very high; Oliver (1980) also suggested that satisfaction is associated with the willing of the future and this correlation militated directly or indirectly through the customer attitude, further satisfaction determine whether or not people will visit a store again in the future. Hsu et al. (2006) ${ }^{[7]}$ proposed that satisfaction had a positive impact on customer repeat purchase intention. So,

Hypothesis 1: Customer satisfaction has a positive effect on customers' repurchase intention in online shopping.

Trust plays a controlling role in the relationship between customers and suppliers when network environment is in a high degree of uncertainty, vulnerable and strong dependence. Because customers can't review online store, experience goods by themselves and guarantee the security of online payment, they reduce uncertainty and complexity of online trading through the application of mental shortcuts under the condition of limited information and knowledge resources. Grabner Kraeuter (2002) ${ }^{[8]}$ argued that trust is one of the effective mental shortcuts. Trust can be used as a mechanism which can reduce the complexity of human behavior under the uncertain environment. We cannot guarantee the seller will not engage in bad speculation due to the limited to the seller's control, so trust becomes an important aspect of online shopping. Chiu et al. (2009) thought that trust is the belief that the trustor believe that the trustee has the ability, benevolence and sincerity. Ability is the principal that the trustee can complete the desired responsibility; Benevolence is the principal that the trustee will not use opportunistic behavior; Sincerity is the principal that the trustee is honesty and complies with the commitment to the trustor. When customers search for online information, the importance of trust cannot be reflected. Only when the customer trade with e-commerce enterprises, the necessity of trust will emerge. Safety is the essential condition in online shopping and it is the responsibility for e-commerce site to improve and keep the trust of the customer. Chiu et al. (2009) ${ }^{[3]}$ showed that the improvement of trust represents a high level of satisfaction and trust can be satisfactory prerequisites in the process of online shopping. Therefore,

Hypothesis 2: Customer trust has a positive effect on customer satisfaction in online shopping.

Fairness may affect trust, because the research suggests that distributive fairness, procedural fairness, interpersonal fairness and information fairness have influence on trust. Pearce (1998) found that procedural justice is related to employees' organizational commitment and partners trust even after the control of economic policy; Pillai et al. (2001) showed that distributive justice has significant positive influence on trust in the United States, Germany, India and Hong Kong and in addition to Hong Kong, procedural justice all have significant positive effect on trust in the other three countries; CohenCharash and Spector (2001) argued that distributive justice and procedural justice have important relationship with organizational commitment and trust; Chiu et al. (2009) discussed the customer loyalty in online shopping by integrating the technology acceptance model, trust and fairness theory and the results showed that distributive justice, procedural justice and interaction justice can significantly expected online customer trust; Zhu and Chen $(2012)^{[9]}$ proved that online customer trust had a key mediation role between fairness and satisfaction and in the study the service fairness is 
composed of distributive justice, procedural justice and information justice; Colquitt et al. (2001) showed that perceived fairness is associated with management and organizational trust and the organizational justice is divided into four dimensions, namely, distributive justice, procedural justice, interpersonal justice and information justice. As a result,

Hypothesis 3: Customer fairness has a positive effect on customer trust in online shopping.

\section{METHODOLOGY}

\section{A. Measures}

The study mainly includes seven variables: distributive justice, procedural justice, interpersonal justice and information justice, online customer trust, online customer satisfaction and customer repeat purchase intention, and the measurement scale is formed by consulting the more mature item and the characteristics of the circumstances of China's network. Moreover, we carried out in-depth interview with twenty consumers to determine the logic of scale and the scientific of semantic expression.

The measurements for distributive justice, procedural justice, interpersonal justice and information justice were all adapted from the study of Teo and Lim (2001) ${ }^{[10]}$ and Chiu et al., $(2013)^{[5]}$. The measurements for online customer trust were adapted from Gefen et al.’s (2003) and Lee et al.'s (2011) study. The items for online customer satisfaction were adapted from Hsu et al.'s (2006) study. The items for online repurchase intention were adapted from Al-Maghrabi et al.'s (2011) ${ }^{[11]}$ study. The variables were measured by seven Likert scale, such as 1 strongly disagree, 7 strongly agree.

\section{B. Sampling}

The research collected data by the questionnaires and investigated customer's perceptions of a familiar shopping website. The respondent contains different age groups, but most should be between the ages of 18 and 35 because online shopping customers are young and easy to accept online shopping. The survey sample major in Chengdu and Chongqing and part of it take convenience sample distributed in the classroom and the library of three different universities, another part of the sample take random sampling and intercept type to obtain samples. A total of 800 questionnaires were issued and at last recycled 610 copies of effective questionnaires, so the recovery rate is about $76.3 \%$, in which the man samples (51.5\%), the woman samples (48.5\%);18-25 years old (44.8\%), 26-30 years old (24.3\%), 31-35 years old(16.7\%); College/undergraduate samples (59.2\%), above master samples(25.9\%); the ratio of network contact time in 13 years, 4-6 years, 7-9 years, respectively, 12\%, 28.5\%, 32.8\%; the ratio of online shopping time in 1-3 years, 4-6 years, 7-9 years, respectively, $47.5 \%, 35.7 \%$, $4.8 \%$.

\section{RESULTS}

The structural equation model is used to analyze the relationship of every latent variable. Firstly the reliability and validity are tested, and then measure the relationship of latent variables in order to discuss the effect of online customer fairness on online customer satisfaction and then on online customer repurchase intention (the hypothesis H1, H2 and H3).

\section{A. The analysis of reliability and validity}

According to the Cronbach' $\alpha$ value and component reliability, the Cronbach' $\alpha$ value of seven latent variables is from 0.869 to 0.913 and the component reliability is from 0.870 to 0.913 , more than 0.7 standard, so all variables show good consistency and the model pass the reliability test; further, the indicator loading of variables are all greater than 0.7 and the AVE value all greater than 0.626, so the model has better convergent validity.

TABLE I. THE AVE, COMPONENT VALIDITY AND CRONBACH’ $\alpha$

\begin{tabular}{|c|c|c|c|}
\hline Construct & AVE & Component validity & Cronbach's $\alpha$ \\
\hline DF & 0.626 & 0.870 & 0.869 \\
\hline PF & 0.693 & 0.900 & 0.899 \\
\hline ITF & 0.714 & 0.909 & 0908 \\
\hline IFF & 0.720 & 0.911 & 0.911 \\
\hline TR & 0.658 & 0.906 & 0.908 \\
\hline SAT & 0.700 & 0.875 & 0.877 \\
\hline RP & 0.677 & 0.913 & 0.913 \\
\hline
\end{tabular}

The table 2 indicated the AVE value and the square of correlation coefficient among latent variables and the AVE value are all greater than the square of correlation coefficient among latent variables, so the discriminant validity is tested.

TABLE II. AVE AND THE SQUARE OF CORRELATION COEFFICIENT BETWEEN CONSTRUCTS

\begin{tabular}{|c|c|c|c|c|c|c|c|c|}
\hline & DF & PF & ITF & IFF & F & TR & SAT & RP \\
\hline DF & 0.628 & & & & & & & \\
\hline PF & 0.397 & 0.693 & & & & & & \\
\hline ITF & 0.311 & 0.369 & 0.714 & & & & & \\
\hline IFF & 0.415 & 0.491 & 0.387 & 0.720 & & & & \\
\hline F & 0.597 & 0.686 & 0.539 & 0.717 & & & & \\
\hline TR & 0.354 & 0.420 & 0.329 & 0.439 & 0.612 & 0.658 & & \\
\hline SAT & 0.181 & 0.214 & 0.169 & 0.225 & 0.314 & 0.511 & 0.700 & \\
\hline RP & 0.090 & 0.108 & 0.080 & 0.113 & 0.158 & 0.257 & 0.503 & 0.677 \\
\hline
\end{tabular}

\section{B. Structural model fit}

The model fit index is as follows: $\chi^{2} / \mathrm{df}=1.832$, $\mathrm{GFI}=0.814, \mathrm{CFI}=0.933$, TLI $=0.926$, $\mathrm{IFI}=0.933$, $\mathrm{RMSEA}=0.063$ and all indicators are better fitting, so the model is fit with the data.

From the regression results (the table 3), the online customer satisfaction has a positive effect on online customer repurchase intention ( $\beta=0.709, \mathrm{P}<0.05$ ), so the $\mathrm{H} 1$ was tested; the online customer trust has a positive effect on online customer satisfaction ( $\beta=0.715, \mathrm{P}<0.05$ ), so the $\mathrm{H} 2$ was tested; the online customer fairness has a positive effect on online customer trust ( $\beta=0.782, \mathrm{P}<0.05)$, so H3 was tested. 
TABLE III. RESULT OF THE STRUCTURAL MODEL

\begin{tabular}{|c|c|c|c|c|}
\hline Hypothesis & $\beta$ & $\mathbf{t}$ Value & $\mathbf{p}$ Value & Result of Test \\
\hline H1 & 0.709 & 9.200 & $* * *$ & ACCEPTED \\
\hline H2 & 0.715 & 9,619 & $* * *$ & ACCEPTED \\
\hline H3 & 0.782 & 8.278 & $* * *$ & ACCEPTED \\
\hline \multicolumn{5}{|c}{ a. ${ }^{*}$ Significant at $\mathrm{p}<.05 ; * *$ Significant at $<<.01 ; * * *$ Significant at $<<.001$}
\end{tabular}

\section{CONCLUSION}

All hypothesizes were tested in the study. Firstly online customer fairness has a significant positive effect on online customer trust, so online vendors should consider the important role of the second-order construct fairness on online customer trust; secondly online customer trust has a significant positive role on online customer satisfaction, because online shopping is a higher risk in virtual environment and customers will be satisfied with the website if they trust it; finally online customer satisfaction has a significant positive effect on online repurchase intention, that is, satisfaction is an important way of improving online customer repurchase intention in e-commerce environment.

The electronic business enterprise should pay attention to improve the online customer perception of fairness which decided by the distributive fairness, procedural fairness, interpersonal fairness and information fairness. Online vendors must provide goods with reasonable price and the same product information. Moreover, they make no discrimination among service, price and relevant policy among different customer. The most important is they must be sincere, friendly and polite to customers, update the logistic information timely and explain the question in the purchase process.

\section{REFERENCES}

[1] Kim H W, Gupta S. A comparison of purchase decision calculus between potential and repeat customers of an online store[J]. Decision Support Systems, 2009, 47(4): 477-487.

[2] Chiu C M, Chiu C S, Chang H C. Examining the integrated influence of fairness and quality on learners' satisfaction and Web - based learning continuance intention[J]. Information Systems Journal, 2007, 17(3): 271-287.

[3] Chiu C M, Lin H Y, Sun S Y, et al. Understanding customers' loyalty intentions towards online shopping: integration of technology acceptance model and fairness theory[J]. Behaviour \& Information Technology, 2009, 28(4): 347-360.

[4] Chiu C M, Wang E T G, Shih F J, et al. Understanding knowledge sharing in virtual communities: an integration of expectancy disconfirmation and fairness theories[J]. Online Information Review, 2011, 35(1): 134-153.

[5] Chiu C M, Fang Y H, Cheng H L, et al. On online repurchase intentions: Antecedents and the moderating role of switching cost[J]. Human Systems Management, 2013, 32(4): 283-296.

[6] Boulding W, Staelin R, Kalra A, et al. "A Dynamic Process Model of Service Quality: From Expectations to Behavioral Intentions[J]," Journal of Marketing Research, 1993, 30(1):7-27.

[7] Hsu M H, Yen C H, Chiu C M, et al. A longitudinal investigation of continued online shopping behavior: An extension of the theory of planned behavior[J]. International Journal of Human-Computer Studies, 2006, 64(9): 889-904.

[8] Grabner-Kraeuter S. The role of consumers' trust in online-shopping[J]. Journal of Business Ethics, 2002, 39(1-2): 43-50.

[9] Zhu Y Q, Chen H G. Service fairness and customer satisfaction in Internet banking: exploring the mediating effects of trust and customer value[J]. Internet Research, 2012, 22(4): 482-498.

[10] Teo T S H, Lim V K G. The effects of perceived fairness on satisfaction and behavioral intentions: the case of computer purchase[J]. International Journal of Retail \& Distribution Management, 2001, 29(2): 109-125.

[11] Al-Maghrabi T, Dennis C, Vaux Halliday S, et al. Determinants of customer continuance intention of online shopping[J]. International Journal of Business Science and Applied Management, 2011, 6(1): 4165. 